Volume. 2 Nomor. 2

Periode: Juli - Desember 2018; hal. 100-105

p-ISSN : 2580-1112; e-ISSN : 2655-6669

Copyrighr@2018

Penulis memiliki hak cipta atas artikel ini

Jurnal Ilmiah Keperawatan Orthopedi (JIKO)

journal homepage:

https://ejournal.akperfatmawati.ac.id

\title{
Gambaran Implementasi Mobilisasi Dini Oleh Perawat Pada Klien Paska Operasi Orif Fraktur Ekstremitas Bawah
}

\author{
Sudarmi $^{1}$ \\ Akademi Keperawatan Fatmawati
}

\begin{abstract}
Abstrak
Berdasarkan standar operasional prosedur penatalaksaan pasien post operasi ORIF ekstremitas bawah, pada 24 jam pertama sebaiknya dilakukan mobilisasi dini bertujuan untuk memperbaiki sirkulasi, mengurangi komplikasi imobilisasi post operasi, mempercepat pemulihan peristaltik usus sehingga mempercepat pemulihan pasien paska operasi. Metode penelitian ini adalah deskriptif, mengambarkan implementasi mobilisasi dini oleh perawat berdasarkan tingkat pendidikan, pengalaman kerja, pelatihan orthopaedi mobilisasi dini dan sumber ilmu yang didapat tentang mobilisasi dini pada pasien. Total sampel pada 31 orang perawat. Dari hasil uji statistik univariat didapatkan bahwa implementasi mobilisasi dini oleh perawat pada pasien post ORIF fraktur ekstermitas bawah, dominan perawat melakukan mobilisasi dini sebanyak 16 orang $(51,6 \%)$ dan tidak melakukan sebanyak 15 orang $(48,4 \%)$ dapat disimpulkan mobilisasi dini masih rendah dilakukan oleh perawat ruangan. Sangat disarankan sebagai refensi penelitian serupa dengan menambahkan jumlah responden dan dari rumah sakit tipe A pendidikan yang lain.
\end{abstract}

Kata Kunci : Implementasi, Mobilisasi Dini, Paska ORIF

\begin{abstract}
Base on standard operating procedures for patient with post operation ORIF of the lower limb, the first 24 hours should be done early mobilization, it aims to improve circulation, reduce the immobilization complications of postoperative, accelerate the recovery of intestinal peristalsis, on the whole will accelerating the recovery after surgery. This research method is descriptive, depict the implementation of early mobilization procedure by the nurse in regard of education level, work experience, training MDs early mobilization and sources of knowledge gained about early mobilization of patients. Total samplesw are 31 nurses. From the results of the univariate statistical test showed that the implementation of early mobilization in patients post ORIF of lower extremities fracture, dominant early mobilization nurses perform many as 16 nurses (51.6\%) and did not do as many as 15 nurses (48.4\%), it could be concluded early mobilization still low implemented by nurses in the ward. Highly recommended as a reference point similar studies by adding the number of respondents and from hospitals type A education to another.
\end{abstract}

Keywords: Implementation, Early Mobilization, Post ORIF

${ }^{1}$ e-mail: n.sudarmiharun@gmail.com 


\section{Pendahuluan}

Umumnya pasien paska operasi ORIF setelah 24 jam bedrest, sehingga dapat terjadinya keterbatasan aktivitas.Mobilisasi dini yang dilakukan oleh perawat di ruangan, dapat memperbaiki sirkulasi, mengurangi komplikasi imobilisasi post operasi, mempercepatpemulihanperistaltik usus, mempercepat pemulihan pasien paska operasi. Melakukan mobilisasi sedini mungkin dapat mencegah terjadinya kontraktur, tromboplebitis, dekubitus, konstipasi sehingga penting dilakukan secara kontinyu. Sebagian besar pasien di rumah sakit harus menjalani mobilisasi, dimanapasien harus tirah baring karena terapi atau penyakit yang diderita.

Pasien yang menjalani post operasi, dianjurkan untuk segera meninggalkan tempat tidur atau melakukan mobilisasi (kozier,2010). Salah satunya pasien yang mengalami paska operasi. Hampir semua jenis pembedahan, setelah 24-48 jam pertama paska bedah, pasien dianjurkan untuk segera meninggalkan tempat tidur.

Menurut casey (2000) berpendapat bahwa bedrest selama 24 jam setelah anestesi spinal tidak dianjurkan lagi. Pasien memang tidak boleh duduk, tetapi pasien masih dibolehkan untuk beraktivitas di atas tempat tidur seperti miring kanan atau miring kiri atau menggerakkan anggota tubuh lainnya asalkan tidak dalam posisi duduk atau berdiri.

Posisi ini berguna untuk mengurangi komplikasi sakit kepala paska anestesi spinal tetapi tetap diberikan analgetik. Disini betapa pentingnyaperan perawat sebagai advokat untuk memberikan pendidikan kesehatan, demi mencapainya terapeutik bersama, sehingga perawat harus memperlihatkanperilaku yang positif. (Carpenito,2002).

Namun mobilisasi dini yang dilakukan di Lantai IV Gedung Soelarto RSUP Fatmawati dilakukan bila sesudah 48 jam, dengan alasan sudah melewati dari efek anestesi dan dilaksanakan secara bertahap mulai dari mobilisasi di tepat tidur dengan miring kanan dan miring kiri, lalu duduk di samping tempat tidur.

Mobilisasi dini ini terus dilakukan hingga klien diajarkan ambulasi dini dan klien mandiri, dan siap sampai klien pulang ke rumah. Sesuai dengan tujuan dari penelitian ini adalah untuk mengetahui gambaran implementasi mobilisasi dini oleh perawat pada klien paska ORIF fraktur Ekstremitas bawah di Gedung Soelarto Lantai Idan Lantai IV RSUP Fatmawati Jakarta.

\section{Metode}

Metode penelitian ini adalah deskriftif, gambaran implementasi mobilisasi dini oleh perawat pada pasien paska operasi ORIF fraktur ektermitas bawah hal ini dilihat dari pendidikan perawat, pengalaman kerja perawat, pelatihan orthopaedi mobilisasi dini perawat dan sumber ilmu yang didapat tentang mobilisasi dini perawat. Pengambilan sampel dilakukan dengan cara total sampling dimana pengambilan data denganmenyebarkan kuisioner kepada 31 orang perawat.

\section{Hasil}

\section{Karakteristik Perawat}

1. Pendidikan perawat

Gambar 1. Distribusi frekuensi menurut pendidikan perawatLantaiI dan IV RSUP Fatmawati

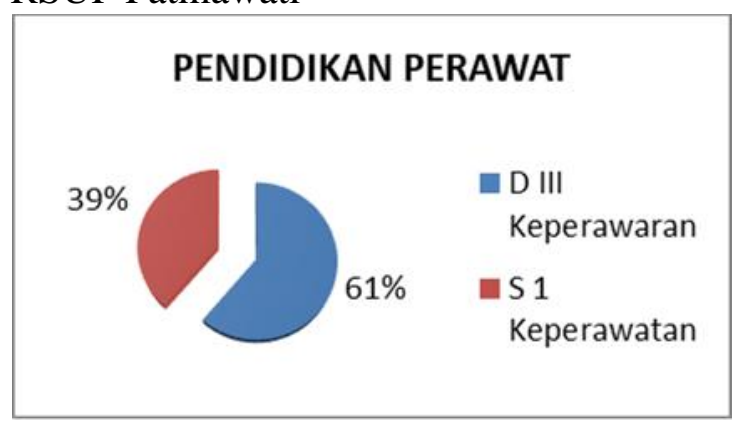

Diagram pie diatas terlihat bahwa D III keperawatan lebih dominan sebanyak 19 orang $(61,3 \%)$.

2. Pengalaman kerja 
Gambar 2. Distribusi frekuensi menurut pengalaman kerja perawat LantaiI dan IV RSUP Fatmawati

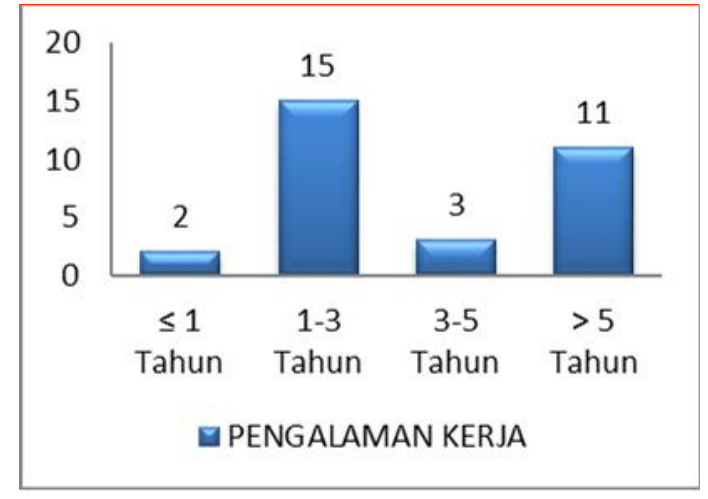

Diagram batang diatas menunjukkan pengalaman kerja terbanyak 1-3 tahun sebanyak 15 orang $(48,4 \%)$.

3. Pelatihan mobilisasi dini

Gambar 3. Distribusi frekuensi menurut pelatihan mobilisasi dini perawat LantaiI dan IV RSUP Fatmawati

\section{PELATIHAN MOBILISASI DINI}

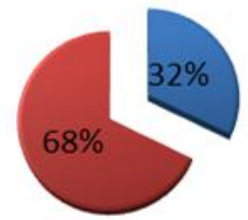

Tidak Pernah

Pernah

Diagram pie diatas terlihat bahwa lebih dominan pernah mendapatkan pelatihan mobilisasi dini sebanyak 21 orang $(67,7 \%)$.

4. Sumber ilmu yang didapat

Gambar 4. Distribusi frekuensi menurut sumber ilmu yang didapat perawat LantaiI dan IV RSUP Fatmawati

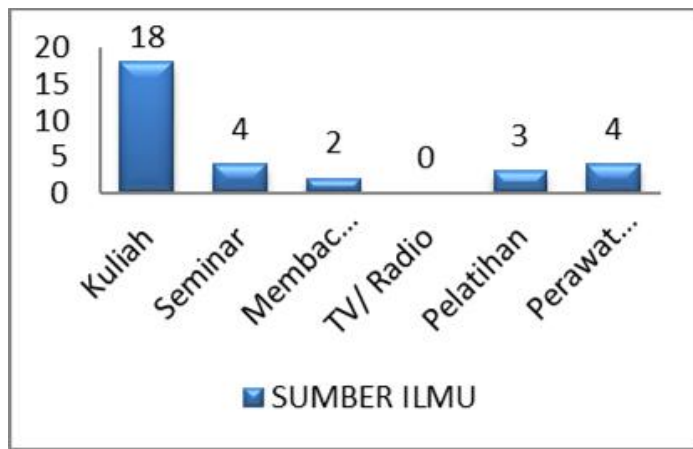

Diagram batang diatas terlihat bahwa sumber ilmu yang didapat tentang mobilisasi dini terbanyak adalah waktu kuliah sebanyak 18 orang $(58,1 \%)$

\section{Analisa Univariat}

Gambaran implementasi mobilisasi dini diukur dengan menggunakan skala likert sebanyak 18 pertanyaan terkait pelaksanaan mobilisasi dini. Total skor responden ini kemudian dapat dikategorikan dilakukan dan tidak dilakukan dengan menggunakan uji normalitas data. Berikut merupakan tabel yang menunjukkan nilai-nilai tersebut.

Tabel 1. Distribusi responden berdasarkan uji normalitas data

\begin{tabular}{cc}
\hline Deskriptif & \\
\hline Mean & 74 \\
\hline Median & 74 \\
\hline Standar Deviasi & 9,42 \\
\hline Nilai minimum & 58 \\
\hline Nilai maksimum & 90 \\
\hline Skewness & $-0,177$ \\
\hline Standar Error & 1,693 \\
\hline
\end{tabular}

Peneliti menggunakan cut of point untuk mengkategorikan implementasi mobilisasi dini responden. Tidak dilakukan implementasi dini jika skor responden kurang dari sama dengan cut of point. Sedangkan dilakukan implementasi dini apabila skor responden berada di lebih dari cut of point. Cut of point yang digunakan peneliti ialah nilai median karena hasil pengolahan data variabel implementasi mobilisasi dini menunjukkan distribusi yang tidak normal. Distribusi tidak normal ini diketahui dari uji normalitas data Kolmogorov-smirnov sig 0,047 <0,05, maka nilai median (74) digunakan sebagai cut of point.

1. Implementasi mobilisasi dini menurut pendidikan perawat

Gambar 5. Distribusi frekuensi implementasi mobilisasi dini menurut pendidikan perawat 


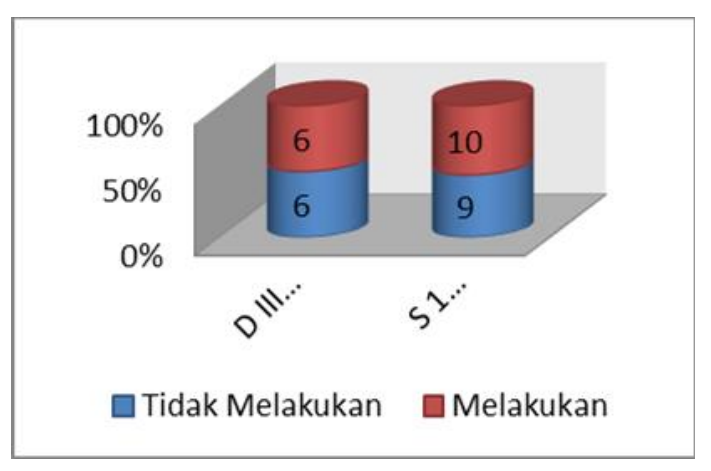

2. Implementasi mobilisasi dini menurut pengalaman kerja

Gambar 6. Distribusi frekuensi implementasi mobilisasi dini menurut pengalaman kerja

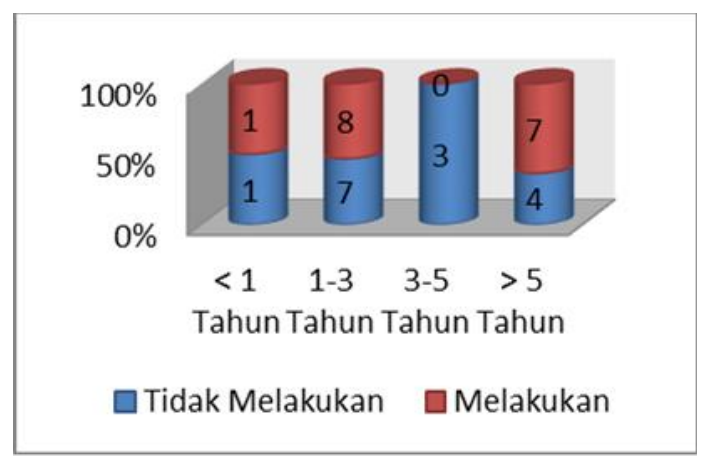

3. Implementasi mobilisasi dini menurut pelatihan mobilisasi dini

Gambar 7 Distribusi frekuensi implementasi mobilisasi dini menurut pengalaman kerja

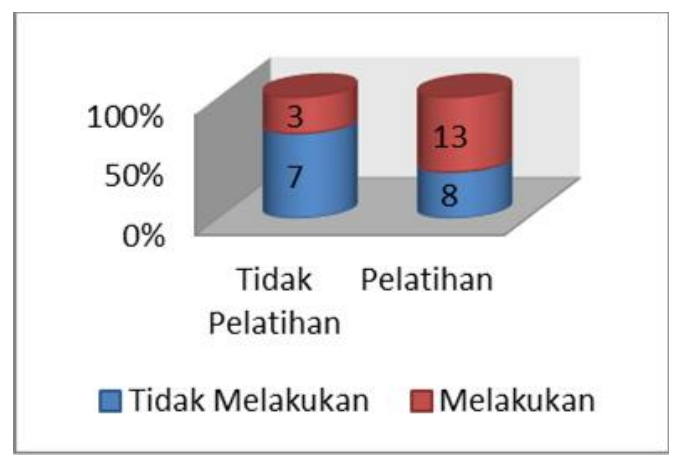

4. Implementasi mobilisasi dini menurut sumber ilmu yang didapat

Gambar 8distribusi frekuensi implementasi mobilisasi dini menurut sumber ilmu yang didapat

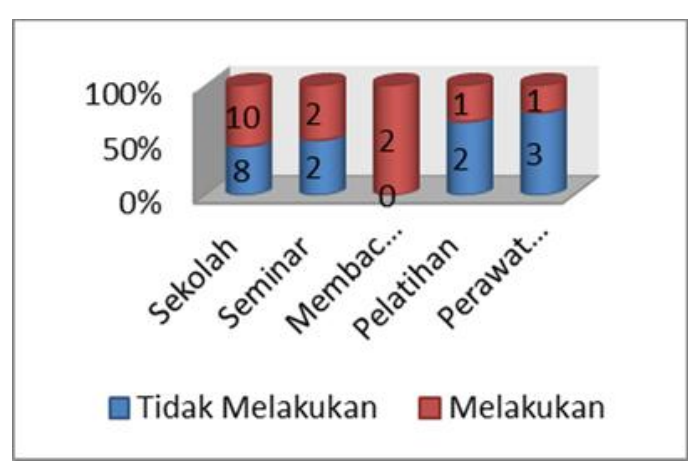

\section{Pembahasan}

Dari hasil uji statistik univariat didapatkan dapat disimpulkan bahwa implementasi mobilisasi dini oleh perawat pada pasien paska ORIF fraktur ekstermitas bawah di dapatkan dominan perawat melakukan mobilisasi dini. Dari hasil tersebut hasil hanya selisih 1 yang berarti tingkat melakukan mobilisasi dini masih rendah padahal mobilisasi dini kurang dari 24 jam sangat bermanfaat terhadap proses kesembuhan pasien.

Pada pelaksanaan implementasi mobilisasi dini oleh S1 Keperawatan terjadi keseimbangan antara yang melakukan dan tidak melakukan. Sedangkan untuk D III Keperawatan lebih dominan dilakukan implementasi keperawatan. Pelaksanaan implementasi perawat $<1$ tahun terdapat keseimbangan antara yang melakukan dan tidak melakukan mobilisasi dini. Untuk perawatyang lama bekerja 1-3 tahun lebih dominan melakukan implementasi mobilisasi dini dibanding yang tidak melakukan, lama bekerja 3-5 tahun lebih dominan tidak melakukan implementasi mobilisasi dini dan yang melakukan tidak ada, sedangkan lama bekerja $>5$ tahun lebih dominan yang melakukan implementasi mobilisasi dini.

Perawat yang tidak mendapatkan pelatihan mobilisasi dini lebih dominan tidakmelakukan implementasi mobilisasi dini, sedangkan yang mendapat pelatihan mobilisasi dini lebih dominan melakukan implementasi mobilisasi dini.

Bagi peneliti selanjutnya hendaknya dapat dilakukan penelitian 
serupa dengan jumlah responden dari beberapa rumah sakit lainnya sehingga dapat memberikan informasi mengenai masalah mobilisasi dini oleh perawat pada klien post ORIF fraktur ekstermitas bawah.

Berdasarkan data pada hasil responden mayoritas responden memiliki pengalaman kerja perawat 1- 3 tahun sebanyak 15 orang lalu urutan kedua pengalaman kerja perawat diatas 5 tahun sebanyak 11 orang, lalu urutan ketiga pengalaman kerja perawat $3-5$ tahun sebanyak 3 orang, dan yang terakhir adalah pengalaman kerja kurang dari 1 tahun sebanyak 2 orang.

Berdasarkan hasil pelatihan diketahui dari 31 responden perawat didapatkan, terbanyak telah mendapatkan ilmu atau pelatihan mobilisasi dini sebanyak 21 orang dan yang belum pernah Kesimpulan

Pada penelitian ini, diperoleh karekteristik responden terbanyak memiliki pendidikan diploma 3 keperawatan dan memiliki pengalaman kerja paling banyak 3-5 tahun masa kerja dan dari hasil penilitian responden didapatkan, terbanyak telah mendapatkan ilmu atau pelatihan mobilisasi dini. Ratarata responden mendapatkan ilmu tentang mobilisasi dini ketika duduk di bangku

\section{Daftar Pustaka}

[1] Anita K, (2012). Faktor-faktor yang berhubungan dengan lama waktu tanggap perawat pada penanganan asma di instalasi gawat darurat RSUD Panembahan Senopati Bantul. Yogyakarta: Lecture Universitas Respati.

[2] Aruan, S dan Suryani (2004) Faktorfaktor yang mempengaruhi klien post operasi fraktur untuk mengikuti mobilisasi secara dini di RSUP Fatmawati. Universitas Indonesia.

[3] Azwar,(1998).Metodologi Penelitian. Yogyakarta: Pustaka Pelajar.

[4] Arikunto, S (2004) Prosedur Penelitian. Jakarta: Bina Aksara, mendapatkan ilmu atau pelatihan mobilisasi dini sebanyak 10 orang. Dengan demikian dapat disimpulkan bahwa sebagian besar perawat di Lantai I dan IV RSUP Fatmawati Jakarta Selatan sudah pernah mendapatkan ilmu atau pelatihan mobilisasi dini.

Berdasarkan hasil penelitian diketahui ilmu yang didapatkan tentang mobilisasi dini mayoritas didapatkan ketika sedang kuliah keperawatan sebanyak 18 orang, lalu urutan kedua terdapat dua yang hasilnya sama yaitu didapatkan dari seminar dan perawat ruangan masing-masing sebanyak 4 orang, lalu urutan ketiga didapatkan dengan pelatihan orthopaedi sebanyak 3 orang, urutan terakhir di dapatkan bahwa dengan membaca sendiri atau dari internet sebanyak 2 orang.

kuliah.Dari hasil uji statistik univariat dapat disimpulkan bahwa gambaran implementasi mobilisasi dini oleh perawat pada pasien paska ORIF fraktur ekstermitas bawah didapatkan dominan perawat melakukan mobilisasi dini sebanyak 16 orang, dan hanya selisih satu dengan yang tidak melakukan mobilsasi dini sebanyak 15 orang dari 31 responden sehingga hasil berimbang.

[5] Asmadi (2008). Konsep dasar keperawatan. Jakarta: EGC.

[6] Brunner \& Suddarth (1996). Text book of medical surgical nursing (third edition). Philadelphia: WB.Saunders Company.

[7] Carpenito, L. J. (2002). Nursing Care Plan Dokumentation Nursing. Diagnosis and Colaboratif Problem.Edisi 2. Jakarta. EGC.

[8] Casey, Wf. (2000). Practical procedures: Spinal Anaesthesia. A Practical Guide. Issue 12 (2000), 1-7. World Federation of Societies of Anaesthesiologists. 
[9] Chandrasekaran,. Kumar,. David (2009). Early mobilization after total knee replacemen reduce the incidence of deep venous thrombosis. Vol.79. Edisi 7-8; pg.526.ANZ Journal of surgery. Oxford.

[10] Craven,R.F and Hirnle,C.J. (2009). Craven and Hirnle's Nursing fundamentals and procedures online. Philadelphia, Lippincot.

[11] Dephub RI. (2006). Keselamatan Transportasi di Indonesia. Jakarta: Direktorat Keselamatan Transportasi Darat. Departemen Pehubungan.

[12] Depkes RI (2009). Berdiri tegak, bicara, bicara lantang, kalahkan osteoporosis. http://www.depkes.go.id

[13] Eldawati (2011). Pengaruh latihan kekuatan otot pre operasi terhadap kemampuan ambulasi dini pasien pasca operasi fraktur ekstremitas bawah di RSUP Fatmawati Jakarta. Depok; Tesis Fakultas Ilmu Keperawatan Universitas Indonesia.

[14] Hastono, S. P. (2007). Basic data analysis for health research training: Analisis data kesehatan. Depok: Fakultas Kesehatan Masyarakat Universitas Indonesia.

[15] Hoeman, S.P. (1996). Rehabilitation nursing: Process and application, $2^{\text {nd }}$ edition. St.Louis: Mirror company.

[16] Kelana, K.D. (2011). Metodologi penelitian keperawatan: Panduan melaksanakan dan menerapkan hasil penelitian. Jakarta: CV. Trans Info Media.

[17] Kozier,B. (2010).Buku ajar fundamental keperawatan : Konsep, proses, praktik, edisi 7, volume 2. (Pamiih Eko Karyani, penerjemah), Jakarta : EGC. (Buku asli : 2010).

[18] Notoatmodjo, S. (2010). Metode Penelitian Kesehatan. Jakarta: Rineka Cipta.

[19] Muttaqin, A (2008). Buku ajar asuhan keperawatan klien .gangguan sistem muskuloskletal. Jakarta: EGC.

[20] Marlitasari, H.(2010) Gambaran penatalaksanaan mobilisasi dini oleh perawat pada pasien post appendiktomy di RS PKU Muhammadiyah Gombong. STiKes Muhammadiyah Gombong. Jurnal Ilmiah Kesehatan Keperawatan, Volume 6, No. 2 Juni 2010

[21] Oldmeadow, B.L,. Lissamaija.N,. Virtanen,H,. Jouko,K,. Sanna,S (2006). No Rest For the wounded: Early Ambulation After Hip Surgery Accelerates Recovery. Royal Australian College of Surgeon, ANZ J.Surg, (76) : 607 - 611

[22] Polit, D.F.\& Hungler, B.P. (2005). Nursing researched principles and methods sixth edition. Philadelphia, Lippincot.

[23] Potter,P.A \& Perry, A.G. (2006). Buku ajar fundamental keperawatan: Konsep, proses, praktik, edisi 4, volume 2. (Renata komalasari dkk, penerjemah). Jakarta: EGC (buku asli:1999).

[24] Rasjad, C. (1998). Pengantar ilmu bedah ortopedi. Ujung pandang: Bintang Lamumpatue.

[25] Reeves, (2001). Keperawatan Medikal Bedah Jakarta: Salemba medika.

[26] Roper. (2002). Mobilisasi pasca Seksio Caesaria, http://www.postsc.com.

[27] Sjamsuhidajat, R., Jong, .(1997). Buku ajar ilmu bedah.Edisi revisi. Jakarta : EGC.

[28] Smeltzer,S. \& Bare,B.G (2009). Textbook of Medical Surgical Nursing, 9th,Philadelphia, Lippincot.

[29] Sugiyono. (2004). Metode Penelitian. Penelitian Bisnis. Bandung : Alfabeta.

[30] Suratun. (2008). Klien Gangguan Sistem Muskuloskeletal, Seri Asuhan Keperawatan. Jakarta: EGC.

[31] Yanti, N.M. (2009) Analisis FaktorFaktor yang mempengaruhi pelaksanaan ambulasi dini pasien post operasi ekstremitas bawah di Rindu B3 RSUP H. Adam Malik Medan. Universitas Sumatera Utara 1 
